Mater. Res. Soc. Proc. Vol. 563, 1999 Symposium M: Material Reliability in Microelectronics IX

\title{
MACROSCOPIC MODELING OF FINE LINE ADHESION TESTS
}

A.A. Volinsky, J.C. Nelson, W.W. Gerberich*

*University of Minnesota, Dept. of Chem. Engineering and Materials Science, Minneapolis, MN

\begin{abstract}
Microwedge Indentation (MWIT) and Precracked Line Scratch (PLST) tests have been developed for adhesion measurements of microscale fine lines. In the MWIT a symmetric wedge-shaped probe is driven downward into a thin film line debonding it from the substrate. For the PLST, a precrack is introduced at one end of a thin metal line on a substrate. The line is loaded from the precrack end by an asymmetric diamond wedge until the crack propagates. When the crack reaches its critical length at a certain critical load, the film buckles.

The mechanics of these tests are based on several assumptions of thin line behavior, which are not experimentally observable due to small line sizes and equipment limitations. Testing similar but larger lines allows for the direct observation of line delamination and buckling, which can be used for calculating in-situ crack lengths as well as instantaneous strain energy release rates.

Both MWIT and PLST models [1-4] were experimentally verified on the macroscopic scale using polycarbonate as a line material bonded to a steel substrate with cyanoacrylate. New features such as initial crack growth as well as instantaneous crack growth at buckling were observed. Modified $\mathrm{K}_{\mathrm{IC}}$ tests were performed for strain energy release rate comparison. Adhesion values ranging from 200 to $1000 \mathrm{~J} / \mathrm{m}^{2}$ were measured for this system, and had very strong mode mixity dependence. Connectivity to the microscale is through previous experiments by de Boer, et al using fine line $\mathrm{W} / \mathrm{SiO}_{2} / \mathrm{Si}$ systems [1-4].
\end{abstract}

\section{INTRODUCTION}

For microelectronics reliability it is essential to know thin film adhesion and to be able to measure it quantitatively. Based on the Linear Elastic Fracture Mechanics (LEFM) approach, two new adhesion tests, the Microwedge Indentation (MWIT) and the Precracked Line Scratch

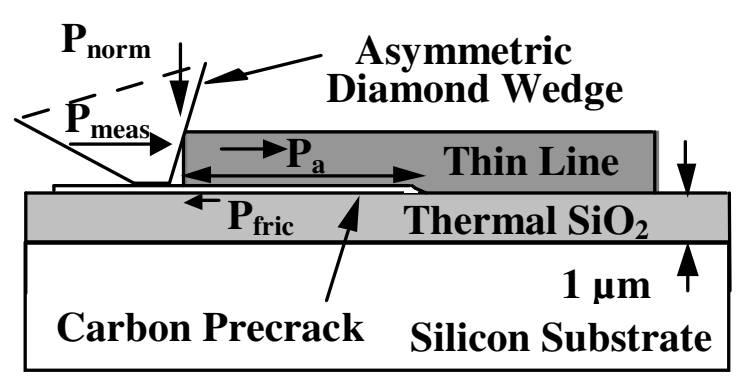
(PLST) tests, have been proposed and performed on the $\mathrm{W} / \mathrm{SiO}_{2} / \mathrm{Si}$ system by Maarten deBoer et al [14]. Both tests are applicable to the thin interconnect lines, and account for thin film geometry. A schematic of the microscopic Precracked Line Scratch test is presented in Figure 1.

\section{Figure 1. Microscopic Precracked Line Scratch} test schematic.

For the PLST a thin metal line on a substrate is pushed from the end with an asymmetric diamond wedge. The thin line has a processed precrack in the form of a carbon layer, which makes it a real fracture mechanics specimen. Only the cracked portion is assumed to deform elastically. The crack propagates along the film/substrate interface until the line buckles at a critical crack length, $a_{\mathrm{cr}}$ (Fixed-fixed end conditions are most applicable in this case):

$$
a_{c r}=\pi h \sqrt{\frac{b h E_{f}^{\prime}}{3 P_{c r}}}
$$

where $\mathrm{h}$ is the film thickness, $\mathrm{E}_{\mathrm{f}}^{\prime}$ is the film's plane strain Young's modulus, and $\mathrm{P}_{\text {cr }}$ is the critical buckling load (maximum load from the load-displacement curve). 
At the point of buckling the strain energy release rate can be calculated as:

$$
\mathrm{G}=\frac{\sigma^{2} \mathrm{~h}}{2 \mathrm{E}_{\mathrm{f}}^{\prime}}=\frac{\mathrm{P}_{\mathrm{cr}}^{2}}{2 \mathrm{~b}^{2} \mathrm{hE}_{\mathrm{f}}^{\prime}}
$$

where $\sigma$ is the stress in the cracked portion of the line, and $b$ is the line width.

For the Microwedge Indentation test (MWIT) a sharp symmetric microwedge is indented into the tested line perpendicular to its axis, and plastically deforms a volume of $2 \mathrm{~V}_{0}$ (Figure 2).

a)

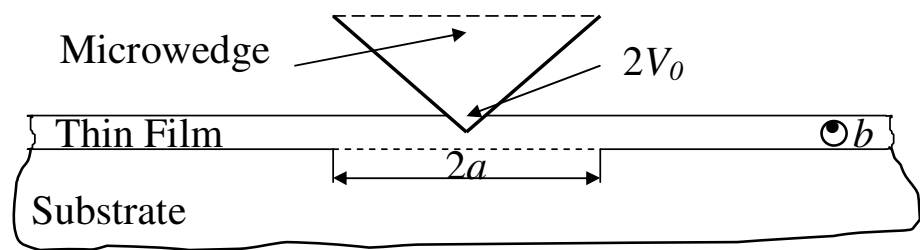

b)

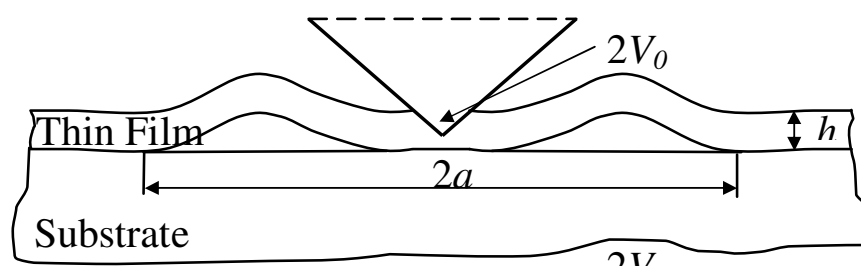

c)

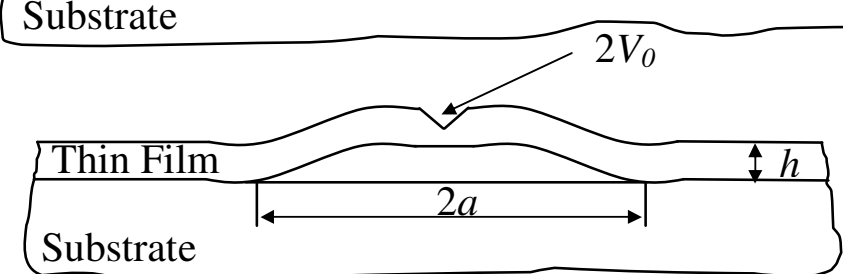

Indentation causes nucleation and propagation of an interfacial crack. If the wedge is indented deep enough, so that the crack reaches its critical buckling length, the film double buckles (Figure 2, b) during indentation. If the crack length does not reach its critical buckling length on each side of the indenter, single buckling might occur upon tip removal (Figure 2, c).

Figure 2. Microwedge indentation (vertical cross section): a) No buckling during indentation; b) double-buckling during indentation; c) single-buckling after the microwedge removal.

When the tip is removed, the film under the indenter is no longer constrainted, so it may form a single buckle even in the initial double-buckling case. For the MWIT the strain energy release rate can be calculated as in [1] on each side of the indenter:

$$
\mathrm{G}=\frac{\mathrm{E}_{\mathrm{f}}^{\prime} \mathrm{V}_{0}^{2}}{2 \mathrm{~b}^{2} \mathrm{ha}^{2}}
$$

where $\mathrm{V}_{0}$ is the half of the total indentation volume, and $\mathrm{a}$ is the crack length.

Both tests are based on several assumptions of thin line behavior, which had not been observed due to small line size and equipment limitations. Testing similar but larger lines allows not only the observation of line behavior, but also the measurement of crack length, which can be directly used for calculating the instantaneous strain energy release rate.

\section{EXPERIMENT}

The MWIT and PLST mechanics can be modeled as a line and a substrate of two different materials bonded together with an adhesive. Polycarbonate (PC) was chosen as the line material because it is transparent for in-situ crack length measurement and would not experience plastic deformation and cracking upon bending for the analysis to be valid. A $1.7 \mathrm{~mm}$ thick, 18 $\mathrm{mm}$ wide by $100 \mathrm{~mm}$ long line was bonded with cyanoacrylate to a 1015 steel substrate mechanically polished to 400 grit. The steel is relatively rigid and tough enough, so it does not crack under the high normal loads in the MWIT. The same materials were used in both MWIT and PLST models with Instron 8500 servo-hydraulic testing machine providing load. Macroscopic test schematics are presented in Figure 3. Tests were video taped and the crack length was measured from the video footage at multiple time steps. 

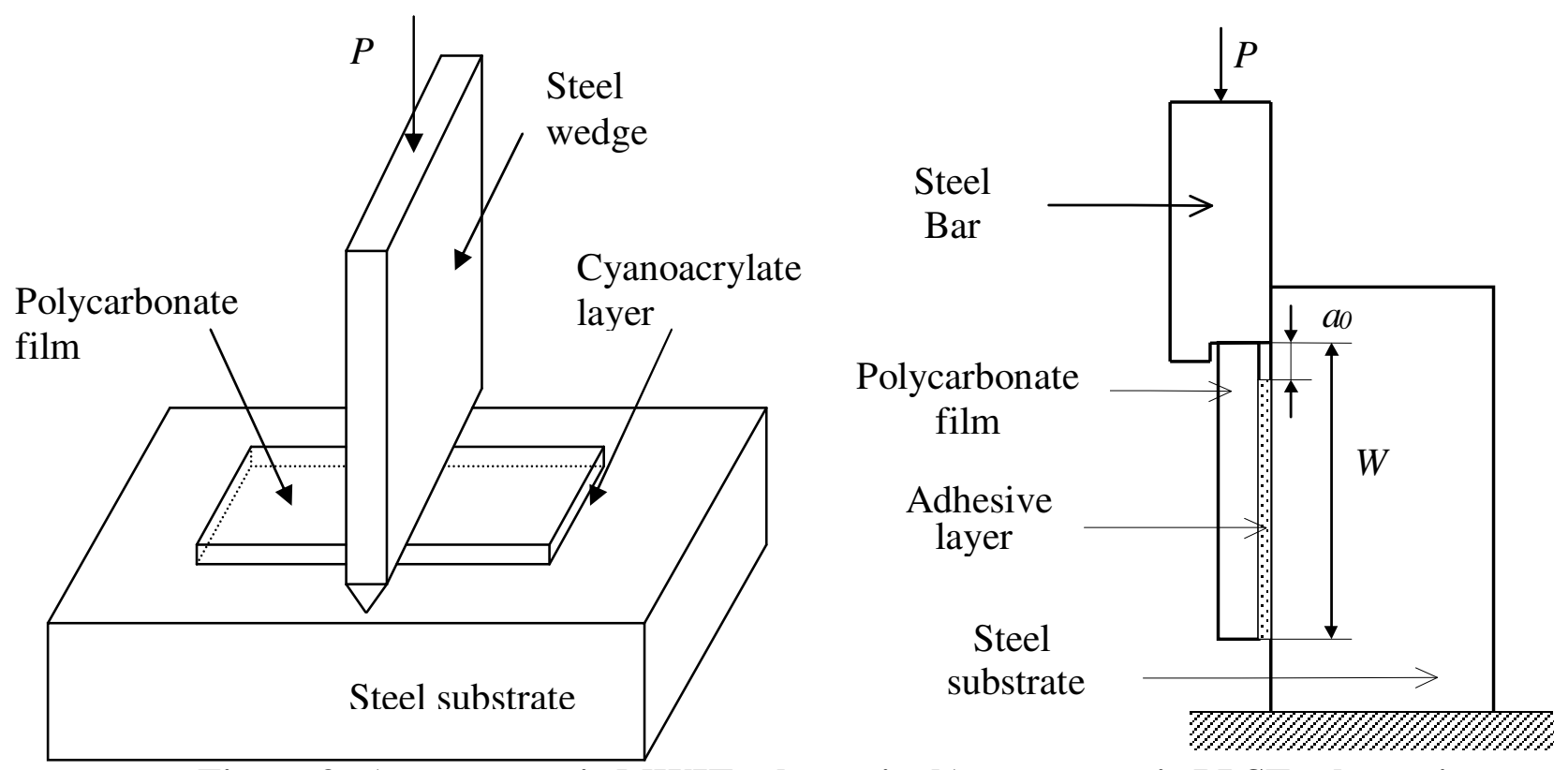

Figure 3. a) macroscopic MWIT schematic; b) macroscopic PLST schematic.

\section{PRECRACKED LINE SCRATCH TEST (PLST)}

The load and crack length are synchronized on the time scale for a given test in Figure 4. In the beginning of the test, the unglued precrack portion of the line $(10 \mathrm{~mm})$ is deformed elastically without the crack propagation. At about $200 \mathrm{~N}$ the crack starts to propagate, mostly in the mode II cracking until it reaches it's critical buckling length of $21 \mathrm{~mm}$ (equation 1). At this

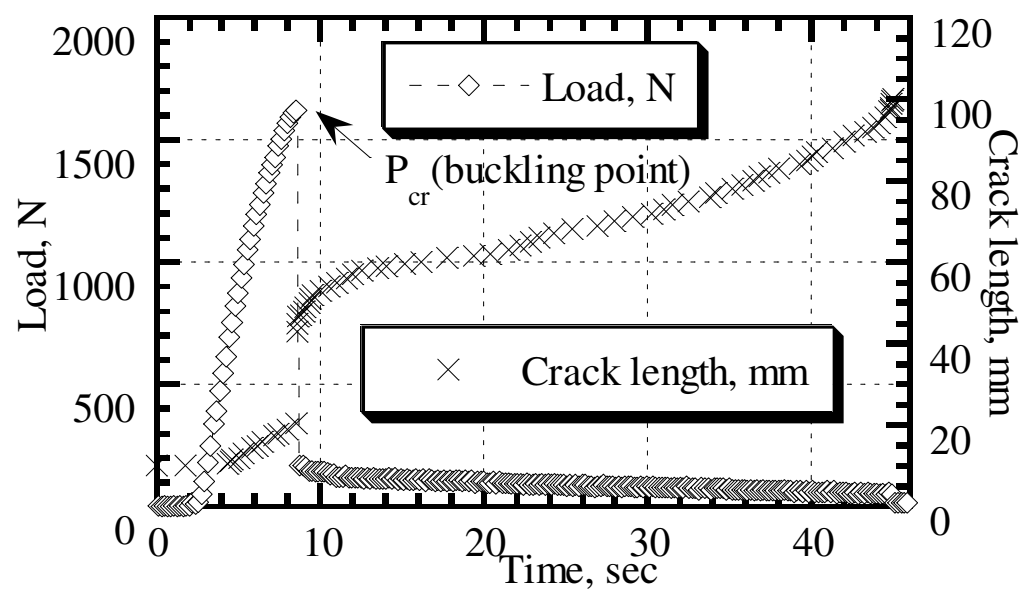
point it rapidly advances about $20 \mathrm{~mm}$ and then continues to grow slowly again after the line buckling. The load drops to zero when the line is totally debonded, and the crack length is equal to the line length. This allowed for the crack length and load data synchronization.

\section{Figure 4. Macroscopic PLST} data.

After buckling the capacity to store strain energy in the buckled film is reduced, so:

$$
\mathrm{U}=\frac{\sigma_{0}^{2}}{2 \mathrm{E}_{\mathrm{f}}^{\prime}} \mathrm{abh}-\frac{\left(\sigma_{0}-\sigma_{\mathrm{b}}\right)^{2}}{2 \mathrm{E}_{\mathrm{f}}^{\prime}} \mathrm{abh}
$$

Here, $\sigma_{0}$ is the stress which would have been induced had buckling not occurred, $\sigma_{\mathrm{b}}$ is the Euler buckling stress:

$$
\sigma_{b}=\frac{\pi^{2} \mathrm{E}_{\mathrm{f}}^{\prime}}{3}\left(\frac{h}{a}\right)^{2}
$$

Using the steel bar displacement, $\delta$, and assuming $\sigma_{0}=\frac{\delta}{\mathrm{a}} \mathrm{E}_{\mathrm{f}}^{\prime}$, we may write: 


$$
\mathrm{U}=\frac{1}{2} \cdot \frac{\delta^{2}}{\mathrm{a}} \cdot \mathrm{E}_{\mathrm{f}}^{\prime} \cdot \mathrm{bh}-\frac{1}{2} \cdot \frac{\left[\frac{\delta}{\mathrm{a}} \mathrm{E}_{\mathrm{f}}^{\prime}-\frac{\pi^{2} \mathrm{E}_{\mathrm{f}}^{\prime}}{3}\left(\frac{\mathrm{h}}{\mathrm{a}}\right)^{2}\right]^{2}}{\mathrm{E}_{\mathrm{f}}^{\prime}} \mathrm{abh}
$$

Since the crack length is known, the strain energy release rate after buckling can be calculated:

$$
\mathrm{G}_{\text {postbuckling }}=-\frac{1}{\mathrm{~b}} \frac{\partial \mathrm{U}}{\partial \mathrm{a}}=\frac{\pi^{2} \mathrm{E}_{\mathrm{f}}^{\prime} \mathrm{h}^{3}}{24 \mathrm{a}^{4}}\left(4 \delta \mathrm{a}-\pi^{2} \mathrm{~h}^{2}\right)
$$

Using the actual load data in equation ( 2 ) for the prebuckling strain energy release rate,

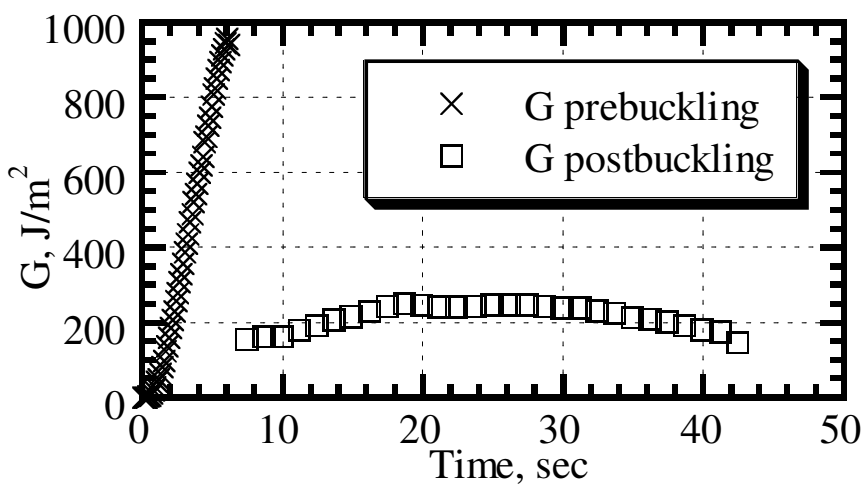
and equation ( 7 ) for the postbuckling rate, Figure 5 can be constructed.

The phase angle, $\Psi$, is $52.7^{\circ}$ at the point of buckling [3]. The strain energy release rate drops from its maximum of $1000 \mathrm{~J} / \mathrm{m}^{2}$ to $200 \mathrm{~J} / \mathrm{m}^{2}$ at the buckling point due to the phase angle change.

Figure 5. PLST strain energy release rate before and after buckling.

Since the maximum load is easily obtained from the load-displacement curve, the maximum in the strain energy release rate was taken as the practical work of adhesion measurement for the microscopic PLST. The macroscopic version of the test allowed constructing the $\mathrm{G}$ curve through the whole length of the test.

Though it did not affect the results, in most of the experiments, the initial crack front was not perpendicular to the line axis due to the upper steel bar misalignment. One might expect the same problem on the microscopic scale.

\section{MICROWEDGE INDENTATION TEST (MWIT)}

The procedure for the indentation test included the following steps:

1. Align the wedge so that it is perpendicular to the polycarbonate line and at the same time parallel to its surface;

2. Penetrate the line at $0.1 \mathrm{~mm} / \mathrm{sec}$ to a predetermined depth $(1-2 \mathrm{~mm})$;

3. Hold the depth constant for 10-30 seconds, monitor the load;

4. Unload fully at the same rate.

The indentation volume was calculated from the indentation depth, measured by means of optical microscopy. First, the microscope is focused on the sample surface, then on the bottom of the residual impression. The indentation depth is taken as the difference between the two focus distances, measured by a micrometer. This procedure was performed on both ends of the indentation, and almost no wedge tilt was noticed.

In most of the tests the indentation depth did not exceed $1 \mathrm{~mm}$, so the crack length did not reach the critical buckling length of $21 \mathrm{~mm}$ from equation ( 1 ) on each side of the indenter. In order to achieve buckling, the test procedure was changed so that instead of going to a predetermined depth, the indenter was stopped when buckling was observed. For most of the tests the asymmetric crack growth on each side of the indenter was observed, which implied high sensitivity to the wedge alignment. Figure 6 shows the load and the depth profiles for the indents driven past the buckling point. Two load drops during loading correspond to the sequential 
buckling events on each side of the indenter. Similar to the macroscopic PLST rapid crack growth was observed upon buckling. Since the strain energy release rate is a function of a crack

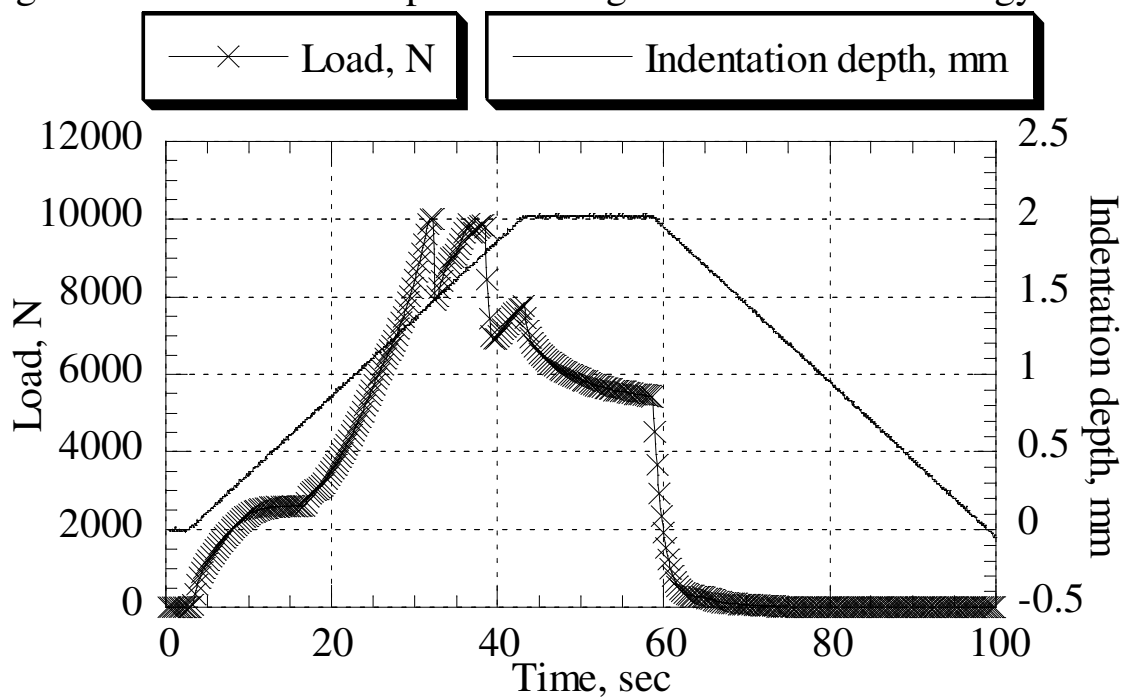
length in equation ( 3 ), overestimating the final crack length due to buckling lowers the actual calculated $\mathrm{G}$ value. The strain energy release rate profile on each side of the indenter for the MWIT is similar to the PLST one (Figure 5).

\section{Figure 6. Macroscopic MWIT load and depth profiles.}

Similar to the PLST, calculated value of the strain energy release rate ranged from 100 to $900 \mathrm{~J} / \mathrm{m}^{2}$ depending on the indentation depth. Elevated fracture resistance values of hundreds of $\mathrm{J} / \mathrm{m}^{2}$ are known for adhesive polymers due to plastic deformation in the adhesive layer $[5,6]$. Since fracture usually occurred through the cyanoacrylate/steel interface, a modified $\mathrm{K}_{\mathrm{IC}}$ fracture toughness test was performed to verify the fracture toughness of the interface in Mode I fracture.

\section{MODIFIED FRACTURE TOUGHNESS K $\mathrm{IC}_{\mathrm{T}}$ TEST}

A standard $\mathrm{K}_{\mathrm{IC}}$ test was performed on the modified CT specimen according to ASTM Standard E399-90 [7]. A steel compact tension (CT) specimen was cut in half. A piece of polycarbonate was glued between two halves of the CT specimen (Figure 7). One side of polycarbonate was bonded with a built in precrack of length $\mathrm{a}_{0}$. The interfacial fracture

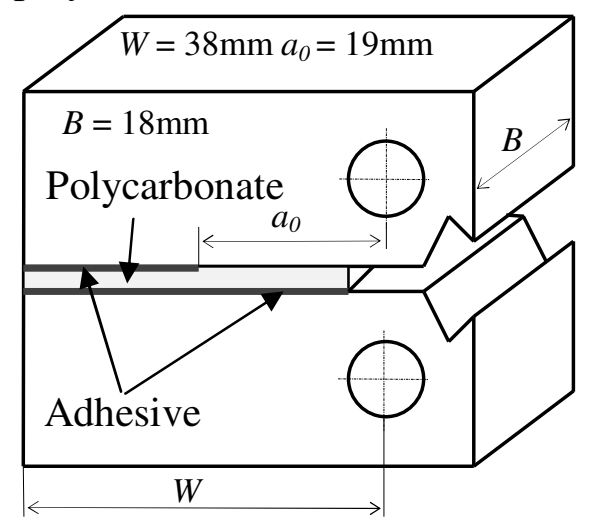
toughness was calculated according to the ASTM standard, based on the peak load and a crack length function. Similar tests with two steel pieces glued together without the PC part were also conducted. Similar values of fracture toughness were calculated, though a steeper loading slope was observed without the PC. An average value of $1.16 \pm 0.25 \mathrm{MPa} \cdot \mathrm{m}^{1 / 2}$ was measured for the interface fracture toughness. A Young's modulus of $6 \mathrm{GPa}$ was measured for the cyanoacrylate by means of nanoindentation [8].

Figure 7. Modified CT specimen.

The corresponding strain energy release rate $\left(G=K^{2} / E^{\prime}\right)[9]$ is $190 \pm 50 \mathrm{~J} / \mathrm{m}^{2}$. Though it was shown that the fracture toughness for a bimaterial interface is somewhat different from the isotropic solution [10,11], we use it as the first order estimate for comparison.

\section{DISCUSSION}

The summary of the macroscopic adhesion tests is presented in Figure 8. Due to the similar phase angle, the postbuckling strain energy release rate values correspond to the $\mathrm{K}_{\mathrm{IC}}$ test 
values. Elevated values of $\mathrm{G}$ prior to buckling can be explained by the phase angle dependence. The interface appears to be tougher in Mode II compared to Mode I fracture.

As expected from the prebuckling portion of the G curve (Figure 5), the MWIT G values before buckling appear to be higher than the postbuckling values, but lower than the buckling ones. Though it is hard to correlate the indentation volume to the crack length at buckling for the MWIT, one data point is presented, and appears to be in agreement with the PLST at buckling.

At buckling the PLST G values appear to be more accurate than the MWIT ones, since they are calculated using the maximum load in equation ( 2 ), and are independent of the crack length. Since the crack length grows rapidly at buckling, the overestimated crack length size measured after the test, provides lower strain energy release rates for the MWIT ( 3 ).

Both tests are very sensitive to alignment. Poor wedge alignment causes an asymmetric crack growth on both sides of the indenter for the MWIT. A curved crack front is also often observed, which results in inaccurate strain energy release rate calculations. Occasionally the

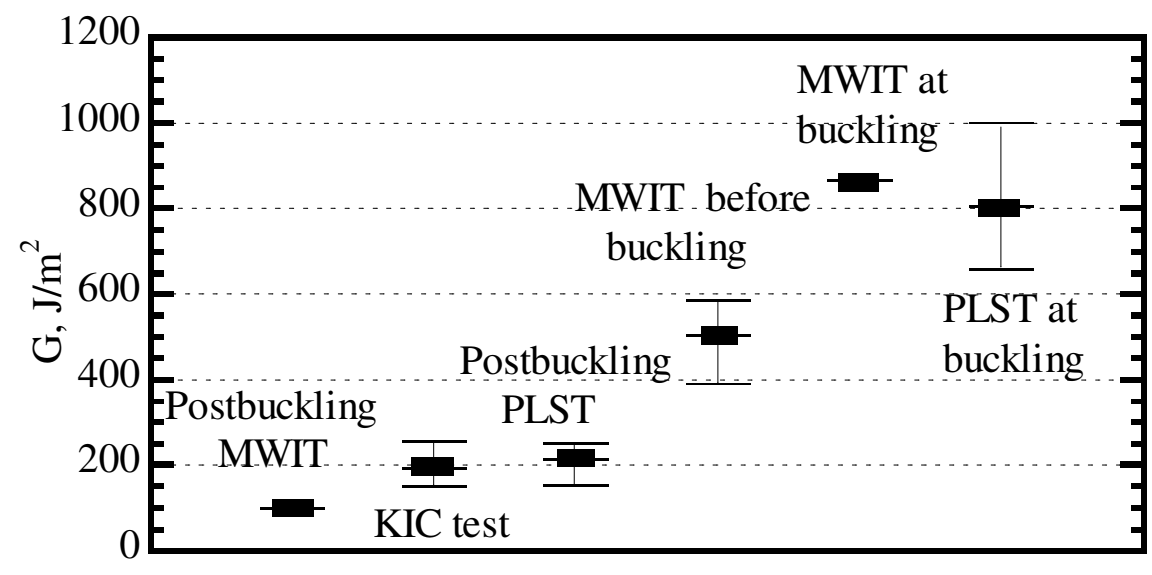
crack front is not perpendicular to the line axis during the PLST prebuckling portion of the test, but it evens out upon buckling and has almost no effect on the measured interfacial toughness.

Figure 8. Macroscopic adhesion tests summary.

\section{CONCLUSIONS}

Macroscopic adhesion tests allowed measuring the crack length at any point of the test for instantaneous strain energy release rate calculations. They showed high sensitivity to instrument alignment and revealed true specimen behavior (unstable crack growth at buckling and asymmetric crack growth for the MWIT). Tests provided reasonable numbers for interfacial adhesion, verified with the modified $\mathrm{K}_{\mathrm{IC}}$ test, thus demonstrating the validity of the PLST and the MWIT mechanics.

\section{REFERENCES}

1. M. de Boer and W. Gerberich, Acta mater. 44 (8), 3169-3175 (1996)

2. M. de Boer, M. Kriese and W.W. Gerberich, J. Mater. Res. 12 (10) (1997)

3. M. de Boer, Ph.D. Dissertation, University of Minnesota, 1996

4. M. de Boer and W. Gerberich, Acta mater. 44 (8), 3177-3187 (1996)

5. R.J. Young and P.A. Lovell, Introduction to Polymers, $2^{\text {nd }}$ ed. (Chapman $\&$ Hall, New York, 1994), p. 398

6. L.H. Sperling, Introduction to Physical Polymer Science, $2^{\text {nd }}$ ed. (John Wiley \& Sons, Inc., New York, 1992), p. 542

7. ASTM Standard 399-90 pp. 407-436, 1990

8. W.C. Oliver and G.M. Pharr, J. Mater. Res. 7, 1564-1583 (1992)

9. H. Ewalds, R. Wanhill, Fracture Mechanics, (Ewald Arnold Publication, London, 1993)

10. Z. Suo, J. Hutchinson, Int. J. Frac. 43, 1-18 (1990)

11. J. Dundurs, J. Appl. Mech. 32, 400 (1965) 